\title{
AFECTIVIDAD Y CONFORMACIÓN DEL SUJETO EN MI VIDA SIN MIY LA VIDA SECRETA DE LAS PALABRASDE ISABEL COIXET
}

\section{AFFECTIVITY AND CONFORMATION OF THE SUBJECT IN $M Y$ LIFE WITHOUT MEAND THE SECRET LIFE OF WORDSBY ISABEL COIXET}

\section{Cristina Monereo Atienza}

Universidad de Málaga, Málaga, España

cmonereo@uma.es

Recibido: mayo de 2019

Aceptado: diciembre de 2019

Palabras clave: Cine y Derecho, teoría feminista del Derecho, afectividad, sujeto de derechos, autonomía relacional.

Keywords: Cinema and Law, feminist theory of Law, affectivity, subject of rights, relational autonomy.

Resumen: En este trabajo me propongo analizar dos películas de la directora catalana Isabel Coixet que reflejan las tesis que apuntan a una naturaleza contradictoria del ser humano donde tiene cabida tanto la individualidad, la autosuficiencia y la justicia, como la socialización, la compasión y el cuidado. De este modo, desde los márgenes del sistema que favorece la reflexión artística, Coixet da cuenta de lo que carece la concepción oficial del sujeto de derechos y del Derecho, especialmente en lo referente al amor o el afecto, apuntando hacia una concepción relacional de los seres humanos que genera un debate sobre la importancia de las relaciones familiares, sobre el trabajo alienante y la necesaria conciliación laboral, y sobre la vida en la esfera privada como ámbito que trasciende a lo público.

Abstract: In this paper I intend to analyze two films made by the catalan director Isabel Coixet, as they reflect the thesis that points to a contradictory nature of the human being. This contradictory nature includes both individuality, selfsufficiency and justice, as well as socialization, compassion and care. In this way, from the margins of the system that favors artistic reflection, Coixet gives an account of what the official conception of the subject of rights and Law lacks, especially in relation to love or affection. In this way, she points towards a relational conception of human beings, which generates a debate on the importance of family relationships, on alienating work and the necessary worklife balance, and on life in the private sphere as a sphere that transcends the public one. 
"Uno de los efectos edificantes del cine consiste en permitir que aquellos individuos cuya sensibilidad ha sido embotada por el predominio de la tecnología y el pensamiento analítico recuperen el contacto sensorial e inmediato de la vida (...) El cine permite, sobre todo al espectador solitario, Ilenar su limitado yo (...) con imágenes de la vida entendida como tal: una vida brillante, alusiva, infinita".

Siegfried Kracauer, 1989: 220

"La tarea actual del cine de mujeres no es la destrucción del placer narrativo y visual, sino más bien la construcción de otro marco de referencia, uno donde la medida del deseo no sea ya el sujeto masculino. Lo que está en juego no es tanto cómo `hacer visible lo invisible', sino cómo crear las condiciones de visibilidad para un sujeto social diferente"

Teresa de Lauretis, 1992: 19

\section{Introducción. La concepción feminista del Derecho y las relaciones entre Derecho y Humanidades}

Desde la dimensión reflexiva y crítica de la realidad jurídica que promueve la Filosofía del Derecho (Díaz García, 1974: 329 y ss.; Ansuátegui Roig, 1995:181; De Castro Cid, 1999: 73; Rivaya García, 2006: 275 y ss.), resultan muy sugestivas las aportaciones de la Teoría jurídica feminista, que ha elaborado una crítica al Derecho en dos sentidos: en primer lugar, ha definido al Derecho en su dimensión discursiva como un producto de sociedades patriarcales, espejo de una visión masculina de la vida, atento a valores, necesidades e intereses de sujetos exclusivamente varones, transcendiendo incluso en oca- siones el nivel de la crítica para proponer una Teoría del Derecho feminista ${ }^{1}$ basada también en una ética del cuidado; en segundo lugar, ha criticado las instituciones jurídicas en las que las mujeres han quedado excluidas o sesgadas (de ahí, las reivindicaciones feministas en el ámbito político, educativo, laboral, familiar); es decir, también se ha ocupado de lo que el Derecho ha silenciado. En este sentido, estoy de acuerdo con Robin West en una cuestión esencial (1997: 262-267): tan importantes son los textos o los discursos, como los aspectos no textuales o no verbales. La visión feminista del Derecho va dirigida a afrontar el poder patriarcal y se ocupa tanto de los aspectos discursivos y, por tanto, del Derecho como discurso, como también de los no discursivos y de la violencia silenciada por el sistema jurídico.

Entre lo discursivo y lo silenciado jurídicamente, la teoría feminista del Derecho concibe una forma distinta del sujeto, radicada en la ignorada concepción relacional e introductora del valor moral y jurídico del afecto y el cuidado tan descuidados desde la Teoría liberal del Derecho y del sujeto. Esta concepción corre más o menos paralela a la propuesta por otras corrientes críticas como la comunitarista (especialmente interesantes son las tesis de Honneth, 1997; también Fraser y Honneth, 2006). Desde esta posición se considera que no se puede obviar lo que de verdad sienten los seres humanos, puesto

1. Para algunos autores es difícil hablar de una Teoría del Derecho feminista en el contexto social patriarcal en el que aún estamos insertos. Así lo entiende Katherine MacKinnon (1989). No obstante, Cristina Jaramillo en el estudio preliminar al libro de Robin West considera que esta autora realiza un intento nada despreciable de Teoría del Derecho feminista en el libro Caring for Justice (1997), cuyo antecedente es el texto que introduce (Jaramillo, 2000: 53). 
que los sentimientos y afectos son consustanciales a la concepción de los individuos. En nuestra herencia cultural esas emociones están mejor expresados en los textos literarios y las obras artísticas.

Adentrarse en el legado cultural-artístico no es, en realidad, una tarea ajena al filósofo del Derecho debido al carácter total de la disciplina que suscita una idea de jurista interesado por multitud de cuestiones y ramas del conocimiento. Entre todas ellas, las Humanidades cuestionan el monopolio de la inteligencia racional en el Derecho, y el desafortunado olvido de la inteligencia emocional, y permiten una visión del Derecho más completa, alimentada por referentes culturales en principio ajenos al ámbito jurídico, capaces de mostrar aquello de lo que ha carecido el esqueleto teórico jurídico tradicional, y especialmente la dimensión afectiva.

Analizar las relaciones entre Derecho y Humanidades desde la crítica feminista es indispensable ya que se apunta hacia la idea de jurista interesado por textos y obras artísticas con el fin de abrirse a la crítica de la teoría formalista del Derecho, poco preocupada por los afectos y cuidados².

Dentro de los estudios de Derecho y Humanidades entendidos de manera general, se incluyen las relaciones entre Derecho y Cine. El cine, como otras artes, ha sido atacado como posible fuente de enseñanza o crítica moral y jurídica por estar plagado de ejemplos considerados inmorales, jurídicamente autoritarios o

2. Robin West explica que ya James Boyd White identificó las reminiscencias del literary lawyer del siglo XIX en el movimiento de Derecho y Literatura, aunque ya en el siglo XX este literary lawyer no busca en la herencia cultural soporte para la autoridad de la ley, sino una fuente de apertura a dicha autoridad (West, 1997: 190 y ss.). machistas (así lo afirma Posner, 2004: 323 y ss.). Desde el punto de vista feminista cabría preguntarse por la utilidad del cine como herramienta crítica de la estructura patriarcal cuando éste ha sido y es todavía en muchas ocasiones discursivamente machista. Se ha llegado a afirmar incluso que el propio medio cinematográfico, en cuanto instrumento que mira un objeto, se corresponde con una visión propiamente masculina (véase el clásico Mulvey, 2009: 63 y ss.). La razón para ocuparse del cine y de las relaciones entre Derecho y Cine para la crítica feminista del Derecho es que, aunque el cine más clásico (especialmente el hollywoodiense) ha manifestado ser principalmente masculino a través de un discurso narrativo naturalizado donde el narrador se esconde formal y materialmente, lo cierto es que el propio medio cinematográfico es un instrumento poderoso a la hora de transmitir emociones y generar empatía, elementos esenciales para la reconstrucción del sujeto relacional de la concepción feminista del Derecho; precisamente por eso en él caben discursos alternativos que incluyan la visión y las reivindicaciones tradicionales feministas. Para esa crítica no es que interesen solamente las películas que se refieren al "mundo de las mujeres", importan aquellas en las que la experiencia diferenciada lleva a dirigir la mirada hacia todo, dando cuenta de que el mundo de las mujeres es también todo el mundo, como el cine de mujeres es cine (Selva y Solá, 2002: 24).

Dentro de las relaciones entre Derecho y Cine, retomando la clásica división realizada en los estudios de Derecho y Literatura $^{3}$, me interesa la dimensión denomi-

3. Para una acercamiento a las relaciones entre Derecho y Cine, propongo retomar la clásica división procedente del movimiento Derecho 
nada "Derecho en el Cine", modelo que analiza la realidad jurídica a partir de una o varias películas. En el ámbito jurídico este es el prototipo más extendido ${ }^{4}$. En los estudios de Derecho y Literatura se ha llegado a defender que ciertas cuestiones jurídicas son tematizadas mejor en las grandes obras literarias que en los propios trabajos jurídicos y que, por tanto, una obra literaria puede ofrecer un mejor conocimiento de una realidad o institución jurídica (por ejemplo, Sansone, 2001: 77 y ss.; Talavera, 2006: 5 y 10; con menos dureza, Marí, 1998: 259). Aunque desde mi punto de vista esta afirmación no es del todo acertada, vuelvo a insistir en la idea de que un texto literario o cinematográfico puede versar sobre una institución jurídica aportando elementos ajenos al acerca-

y Literatura (Law-and-Literature Movement). El esquema clásico es tripartido: Derecho en la Literatura (Law in Literature), Derecho como Literatura (Law as Literature), y Derecho de la Literatura (Law of Literature). De este modo, se podrían distinguir tres modelos de estudio de las relaciones entre Derecho y Cine: el Derecho en el Cine, el Derecho como Cine y el Derecho del Cine. De todos modos, existen igualmente otras divisiones. Andrés Botero, por ejemplo, propone una clasificación distinta y es crítico con esta clásica división, sobre todo en el sentido pedagógico. Diferencia, por ello, los siguientes modelos de la relación, que según explica, son más concretos: retórico, expositivo, metodológico, analítico, jurídico y estético (véase Botero, 2008: 29-40).

4. Junto al movimiento de Derecho y Literatura, los estudios jurídicos en España han mostrado especial atención a las relaciones entre Derecho y Cine, de las que existe ya numerosa bibliografía. Véase en nuestra disciplina de Filosofía del Derecho, por ejemplo: Rivaya García, 2004; Soto Nieta, 2004; Presno Linera, 2006; González Romero, 2006; Ortega y Cremades, 2008; Rivaya García, 2008: 1059-1082; García Manrique, 2009; Rivaya García, 2010: 81-118; Id., 2010: 219-230; Id., 2012: 145-188; Calvo González, 2014: 280-307. miento formal propio del ámbito jurídico y, por tanto, dando a comprender y revelando aspectos desconocidos de esa realidad del Derecho. No se trata simplemente de entender que una película puede sugerir temas de discusión jurídica, sino de analizar también la forma o manera que tiene la imagen para apoyar, complementar, difundir o criticar un determinado mensaje ideológico-jurídico. No se puede obviar el enorme poder de la imagen en movimiento como medio ideológico, donde el mensaje jurídico también se despliega ${ }^{5}$.

Teniendo en cuenta esta triple perspectiva (filosófico-jurídica, feminista y humanística), propongo realizar un acercamiento a las aportaciones realizadas desde parte de la filmografía de la directora Isabel Coixet; particularmente, me referiré a dos de su trabajos cinematográficos Mi vida sin mí (2003), y La vida secreta de las palabras (2005), porque creo que aúnan a la perfección la poética cinematográfica de esta directora catalana 6 .

En un primer punto introduzco la concepción feminista del sujeto relacional, aunque de manera evidentemente resumida

5. De las imágenes se ocupa el giro visual (visual turn) del Derecho. Sobre el estudio de la imagen y el Derecho, dentro de esa tendencia que trabaja el giro visual (pictorial o visual turn) del Derecho, véase por ejemplo Calvo González, en prensa.

6. La obra de esta directora se puede ver como un conjunto en el que se identifica un estilo, unas temáticas, unos mismos tipos de personajes. No me referiré a sus interesantes cortometrajes (Mirá y verás, 1984) o documentales (por ejemplo, Viaje al corazón de la tortura, 2003); o largometrajes como Demasiado viejo para morir joven (1986, estrenado en 1988), Cosas que nunca te dije (1995), A los que aman (1998); u otros largometrajes como Elegy (2007) que fue un encargo, Mapa de los sonidos de Tokio (2009) o su film más reciente La librería (2017). 
(de hecho habría que profundizar más en algunas de las afirmaciones que realizo). En un segundo punto reconstruyo esa concepción desde los textos cinematográficos y, sobre todo, desde los silencios y la imágenes de la filmografía de Coixet.

\section{La concepción relacional feminista del sujeto}

Las críticas feministas al sujeto liberal, supuestamente universal, autónomo, autosuficiente y decididamente androcéntrico se basaron principalmente hasta los años setenta u ochenta del siglo pasado en una confrontación diferencial entre el sujeto masculino y el otro sujeto, el femenino. A nivel de la teoría antropológica, psicoanalítica, o social se enfrentaron dos tesis: la tesis masculina de la separación, y la tesis femenina de la conexión. Robin West resume muy bien ambas posiciones ${ }^{7}$.

La tesis masculina de la separación es la tesis liberal por excelencia, la impuesta oficialmente y, por tanto, la más extendida. Según esta perspectiva, el sujeto es un individuo físicamente separado de otros seres humanos; el ser humano es singular, y lo que le aparta de otros es epistemológica y moralmente anterior a lo que le une a otros; el sujeto es un ser autónomo, autosuficiente, independiente, libre en su elección de vida, de manera general egoístamente motivado, pero también racional y prudente $\mathrm{y}$, por

7. Robin West confronta estos dos modelos en el artículo "Jurisprudence and gender" (1988), más tarde publicado en español en forma de libro "Género y Teoría del Derecho" (2000: 69 y ss.) No obstante, su postura no es esencialista y, de hecho, el esencialismo se utiliza más como herramienta o estrategia. Su anti-esencialismo es después desarrollado en su libro Caring for Justice (1997). eso, tendente al libre contrato. Afirma Robin West: "la experiencia subjetiva de la separación física del otro determina tanto lo que valoramos (la autonomía) como lo que tememos (la aniquilación)" (2000: 81). La teoría del Derecho por excelencia, la liberal, se adhirió a esta tesis de la separación y, por tanto, es esencialmente masculina. Desde esta perspectiva la dignidad humana se reconduce a la capacidad de respetar los derechos de los independientes e iguales, e inferir cognitivamente de esos derechos una reglas para una vida segura. La libertad como no interferencia y la seguridad son los valores clave de la dignidad en esta concepción.

Por su parte, la tesis de la conexión considera que los seres humanos no están separados. La teoría feminista, con sus múltiples diferencias, defendió esta tesis basándose en la experiencia de las mujeres, que están conectadas a otros en al menos varios momentos de su vida, como el acto sexual, el embarazo y la lactancia; y existencial y por supuesto también culturalmente unidas a otros a través de sus vida moral y sus prácticas. De nuevo aquí, hay un temor: "Mientras que los hombres temen la aniquilación por parte del otro (y en consecuencia tienen la dificultad para alcanzar la intimidad), las mujeres temen la separación del otro (y en consecuencia tienen la dificultad para alcanzar la independencia)" (West, 2000: 96). Desde esta visión, la dignidad depende de respuestas afectivas, relacionales, contextuales y soportadoras de las necesidades de los otros. Los seres humanos no son autónomos en el sentido liberal, esto es autosuficientes, sino que alcanzan su autonomía gracias a la relación con otros seres humanos.

Desde los feminismos cultural en EEUU o feminismo de la diferencia en Europa de aquellos años, se afirmaba que la 
teoría femenina de la conexión se oponía drásticamente a la tesis masculina de la separación, y se criticaba por sesgada y masculina la versión oficial del sujeto implantada en la teoría del Derecho.

Actualmente, desde el feminismo se ha reconsiderado esta postura al entender que la confrontación radical de un supuesto modelo femenino de sujeto y otro opuesto masculino peca de binarismo esencialista entre hombres y mujeres dejando fuera, como bien advertía Judith Butler, otras posibilidades ${ }^{8}$. También tiende al reduccionismo de la vida a la confrontación del valor autonomía como autosuficiencia versus el valor del cuidado en base al amor maternal, además de simplificar las relaciones sociales basándolas únicamente en el libre contrato o, por el contrario, en unas relaciones determinadas en base a la reproducción.

Al mismo tiempo, el feminismo confluyó con la teoría crítica comunitarista en el ataque al sujeto separado y autosuficiente, haciendo hincapié en la tendencia socializadora y conectiva del ser humano. Estas propuestas son sumamente

8. Ya autoras como Monique Wittig se distanciaron de sus coetáneas reivindicando la supresión de las categorías hombre-mujer: Wittig, 2000: 29 y ss. El libro de Butler es fundamental para subvertir desde los márgenes la subjetividad: Butler, 2007. En este sentido es interesante advertir también que mucho antes Nietzsche, Heidegger, Sartre entre otros cuestionaron ya el sujeto moderno, y posteriormente Foucault, Derrida y Deleuze acaban trazando los caminos hacía la creación de una nueva subjetividad. Foucault al sostener que el sexo no es algo natural sino construido. Deleuze enfatizando que la subjetividad es múltiple y fragmentada. Derrida al apostar por la diferencia, por un sujeto que se rescribe indefinidamente. Este línea fue tomada por el tipo de feminismo que cito. Un resumen de estas aportaciones está en García López, 2016: 103 y ss. atractivas, siempre y cuando no formulen identidades esencialistas. Menciono más adelante la propuesta de Axel Honneth, que me parece particularmente llamativa. No obstante, esta perspectiva comunitarista nunca ha advertido que la tesis de la separación ha sido tradicionalmente masculina, además de blanca y heterosexual, que fue lo lúcidamente propugnado por algunas tesis feministas. Es necesario poner de relieve esta asociación (separación-masculina, conexión-femenina), aunque la tesis de la separación sea falsa para los hombres y la de la conexión dudosa respecto a determinadas mujeres.

La tesis de la separación es falsa en relación a las mujeres, y tampoco es cierta respecto de los hombres que igualmente experimentan la conexión y pueden sustentar la vida, proteger, atender, amar y afirmar la vida. La tesis de la conexión no es cierta respecto a las mujeres porque no todas quedan embarazadas o son penetradas sexuales (West, 2000: 175-176).

Ciertamente, la experiencia humana (de todos los seres humanos) es siempre contradictoria. El ser humano valora la autonomía y teme la alienación, y al mismo tiempo valora la conexión, pero teme la aniquilación. Como ya afirmaba Ducan Kennedy, el otro es a la vez necesario para nuestra existencia y una amenaza para la misma (Kennedy, 1979: 209).

Estas contradicciones humanas han de reflejarse en la teoría del Derecho. El mayor problema es que la experiencia que tradicionalmente han expresado las mujeres se ha silenciado jurídicamente y es aún necesario visibilizarla. Esta es la razón por la que, ya negando el esencialismo en las categorías binarias masculino-femenino, gran parte de la crítica feminista al 
Derecho siga dirigiéndose en esencia a la supuesta neutralidad estatal que esconde una visión arbitraria y no imparcial del ser humano y de la vida, y en particular de las mujeres.

En la esfera político-jurídica, aun se precisa reivindicar la conjunción de la ética del cuidado con una ética de la Justicia ${ }^{9}$, dirigida a reestructurar instituciones y prácticas como las familiares, las laborales y la separación entre espacio público y privado. La duda es si esto puede hacerse desde dentro del sistema manteniendo categorías clásicas (hombre, mujer) aunque sea de manera estratégica, o por el contrario desde los márgenes en los que es posible idear otras maneras de entender la subjetividad (en este sentido caminan las teorías queer, por ejemplo).

La filmografía de Coixet pone de manifiesto esa tendencia humana contradictoria a la oficialmente impuesta sobre la individualidad, la autosuficiencia y la mera justicia, y a la vez complementaria de ésta que muestra la ineludible socialización, compasión y preciso cuidado. De este modo, desde los márgenes del sistema que favorece la reflexión artística, da cuenta de lo que carece la concepción oficial del sujeto y del Derecho, apuntando hacia un debate sobre la importancia de las relaciones familiares, sobre el trabajo alienante y la necesaria conciliación laboral, sobre la vida en la esfera privada como ámbito que trasciende a lo público.

\footnotetext{
9. Robin West defiende una teoría donde ambas éticas se complementen, y introduce que es la justicia sin cuidado (integridad sin compasión, imparcialidad sin relación, consistencia sin cuidado) y el cuidado sin justicia (cuidado sin consistencia, compasión sin integridad, particularidad sin escalas de justicia): West, 1997: 22-93.
}

\section{El cine de Isabel Coixet: ese saber situarse en lugar del otro y el colocarse en el dolor ajeno}

Decía Siegfried Kracauer, siguiendo a Walter Benjamin, que el cine estaba dotado para registrar y revelar la realidad física (Kracauer, 1989: 51) de tal manera que uno siente que está viviendo la película proyectada y se identifica con los personajes. La ilusión Ileva al espectador a sentir como si hubiera participado en la película, y de este modo como si hubiera vivido los acontecimientos. El cine devuelve la sensibilidad al espectador que es entonces capaz de vivir empática y afectivamente las vidas de otros para conocer mejor su identidad y participar activamente en lo que es la vida. Para conocer la vida y sobre todo para conformarse a uno mismo hay que conocer a los otros, vivir en y a través de otros.

Con anterioridad, Serguéi Eisenstein afirmó que el elemento principal del cine es el espectador al que se intenta provocar una emoción. El autor debe presentar una narración lógicamente coordinada, pero no solamente eso, además ha de provocar el máximo de emoción y poder estimulante (Eisenstein, 1974: 15). El montaje ayuda a que el espectador, a través de su inteligencia y también sus emociones, marche por el camino recorrido por el autor al crear la imagen. La imagen de una escena, de una serie, o de una creación completa no existe como algo fijo y ya terminado; tiene que surgir y desplegarse a través de los sentidos del espectador (1974: 25). El espectador no ve un resultado final, sino que participa y vive el proceso y el sentido. El camino sería de la imagen a la emoción y de esta 
a la idea (Eisenstein, 1970: 333). Es esencial que el cine emita y haga surgir emociones para que el espectador se identifique y viva el sentido y la idea. Eisenstein afirma que "es de emociones humanas y de humanas experiencias, que el cine debe construir sus orígenes estructurales" (1970: 207).

Pues bien, Isabel Coixet realiza auténtico cine al basarse en esta forma emocional y empática de entender el medio fílmico, y eso le permite ofrecer a través de éste un discurso alternativo sobre el sujeto y sus relaciones con otros, mostrando esa visión particular que tradicionalmente ha sido denominada como femenina, aunque yo preferiría llamarla simplemente humana ${ }^{10}$.

Esa visión relacional se consigue, en primer lugar, por los recursos técnico-artísticos que utiliza, principalmente el uso de la cámara en mano que, en palabras de la propia directora, se apoderó de ella por las posibilidades que ofrecía para transmitir la intensidad de las emociones, viviéndolas casi en persona ${ }^{11}$. Su cine es muy intimista y emocionalmente intenso, y en él abunda la voz en off para emitir los sentimientos más profundos de los protagonistas. En segundo lugar, se logra por la utilización de otros lenguajes, del silencio y de las imágenes para comu-

10. El intentar separar las creaciones artísticas de mujeres y hombres en estilo formal y temática tiene sentido para reivindicar la versión femenina que se ha ignorado, pero pienso que no puede hacerse de manera esencialista, como si las mujeres fueran las únicas capaces de hacer obras intimistas, emocionales y compasivas. No lo creo. Un ejemplo en el ámbito cinematográfico es Deseando amar (2000) de Wong Kar Wai.

11. Así lo informa la directora en la entrevista que le realiza Rafael Cerrato: Cerrato, 2008: 143-144. nicar cosas que no se pueden expresar hablando: muchas escenas se resuelven a través de silencios; hay muchos planos en los que el contenido se desprende únicamente de imágenes de gran fuerza visual; los planos, que suelen ser primeros o primerísimos planos, son montados a conciencia según el ritmo rápido o lento de lo que se quiere transmitir. En tercer lugar, está la historia y la caracterización de los personajes. Coixet crea historias que obligan a reflexionar sobre los recodos del comportamiento humano, sin que al final podamos saberlo todo de los personajes. Sus protagonistas son solitarios, esconden grandes secretos, y están generalmente alienados en sus trabajos y en sus vidas cotidianas en el marco de una sociedad capitalista. En sus historias hay siempre un despertar de esa alienación y un redescubrimiento de la magia de la vida cotidiana, encontrando de nuevo el placer de probar una buena comida, de sentir el sol y la lluvia, de hablar con los compañeros, de abrazar a los seres queridos, etc...La misma Coixet homenajea a John Berger en algunas de sus películas por su intención de sacralizar lo cotidiano (Cerrato, 2008: 138).

Su primera película de éxito, Mi vida sin mí, trata sobre una mujer, Ann (interpretada por Sarah Polley); es una chica en cierta manera alienada por su pobreza y modo de vida, que le diagnostican un cáncer terminal, y que decide no decir nada a sus seres queridos y vivir intensamente los dos meses que le quedan, recuperando el valor de las pequeñas cosas y preparando la vida de los que le rodean para que no sufran su ausencial2.

12. Tráiler oficial: https://www.youtube.com/ watch?v=JTgkNC1MX6w (última consulta 12 de noviembre de 2018). 
En su largometraje posterior La vida secreta de las palabras la protagonista es Hanna (también interpretada por Sarah Polley), una víctima sorda de la guerra de los Balcanes, que intenta sobrellevar su pasado trabajando sin cesar en una fábrica cuando en unas forzadas vacaciones se ofrece voluntaria para el cuidado de un persona (Tim Robbins), quien ha sufrido un incidente grave en una aislada plataforma petrolífera. Su relación con ese individuo es lo que le hace retomar su vida ${ }^{13}$.

Estos son las películas en las que me gustaría profundizar en este trabajo. En ambas el despertar de la alienación y el encuentro de la propia subjetividad se producen gracias a la relación y la empatía con los otros. De las dos historias se desprende que la afectividad, la empatía y compasión con los otros configuran los seres humanos, y que éstas conforman un estado previo para la comunicación.

Este problema, tan discutido en el ámbito de la Filosofía, plantea que para ser individuos realmente autónomos antes de la comunicación con otros está la relación con los otros, y por tanto primero es el amor y la devoción hacia uno mismo y por el otro. Como afirma Axel Honneth la autoconfianza, el autorrespeto y la autoestima de los individuos se adquieren gracias a un proceso intersubjetivo en el que el sujeto toma conciencia de sí mismo y de los demás como seres iguales y dignos ${ }^{14}$.

13. Tráiler oficial: https://www.youtube.com/ watch?v=AYHfZ_GOqPw (última consulta 12 de noviembre de 2018).

14. Véase por ejemplo el diálogo entre Jürgen Habermas y Axel Honneth (teoría del discurso versus teoría del reconocimiento). Honneth se centra en la noción de reconocimiento recíproco, porque va más allá del hecho de que uno se ponga en el lugar de un segundo interlocutor, y plantea que antes de ponerse en el lugar del otro,
Resuenan aquí las ideas de Hegel en el que el desarrollo de la identidad personal de un sujeto está ligada al presupuesto de actos de reconocimiento por parte de otros sujetos. Si uno no reconoce al otro en la interacción como un determinado tipo de persona, tampoco puede verse a sí mismo como ese tipo de persona (Honneth, 1997: 50 y ss.).

Desde esta perspectiva los seres humanos son seres sociables, y la mediación con el mundo es siempre a través del lenguaje. Sin embargo, la comunicación no se da entre seres humanos independientes y separados; es entre seres con lazos previos de reconocimiento mutuo. Solamente tras el descubrimiento del yo en los otros es posible la comunicación. Sin el estado previo de consideración por el otro, la comunicación no es efectiva, y puede fallar.

Rafael Cerrato, autor del cuento que inspiró la película de Mi vida sin mí, explica que el tema del lenguaje es fundamental en el trabajo de la directora catalana, especialmente el problema de comunicación entre los individuos (2008:143 y ss.).

En Mi vida sin mí Ann es aparentemente feliz: está dichosamente casada con Don (Scott Speedman) al que ama, tiene dos hijas a las que adora, y tiene trabajo. A pesar de ello, no es realmente feliz y hasta que no conoce su enfermedad es incapaz de expresarlo con palabras al ser su frustración fruto del contexto complejo en el que vive (esto es, del hecho de que es pobre y se ve obligada a trabajar pero precariamente y de manera nocturna; de que su casa no es más que una caravana en el patio trasero de su madre; de que

antes del «conocimiento» del (y comunicación con) otro, se requiere previamente un «reconocimiento» basado en el amor. Honneth, 2007. 
Don es el único hombre con el que ha estado y es, en palabras de las misma Ann, un desastre ${ }^{15}$; de que su madre siempre se queja porque no ha sabido salir del círculo que la oprime; y sobre todo de que fue madre demasiado pronto a los 17 años por lo que no ha podido desarrollar íntegramente su personalidad). En un momento de vómitos y nauseas en el trabajo, Ann se retrotrae a experiencias pasadas de humillación, que le sucedieron cuando niña, como aquella que vez que se rieron de ella en el colegio (escena 1). De repente verbaliza experiencias frustrantes en las que la falta de empatía de otros han impedido el reconocimiento de su propio yo. De sus palabras se deduce lo que podía haber sido, puesto que es una chica inteligente que podría haber estudiado, por eso aprende chino escuchando cintas a todas horas; también comprendemos que le hubiera gustado viajar, y de ahí que le encante, a la vez que le entristece, que el personaje de Lee (Mark Ruffalo), un chico que se enamora de ella, quiera llevarla a ver sitios maravillosos en Chile o Argentina; y concluimos en suma que le hubiera gustado ser y hacer tantas otras cosas si hubiera tenido realmente la oportunidad de haber decidido sobre su propia vida; sin embargo, como su madre, no ha podido abstraerse de su contexto, de ser madre joven o tener un trabajo precario. Esto no debe tomarse como una crítica hacia ella, sino como un ataque a la noción de autonomía como autosuficiencia. Es muy difícil abstraerse del contexto ya que este incide muy especialmente en la toma de decisiones de los individuos.

Otra escena interesante en Mi vida sin mí respecto a los problemas de comunicación

15. Lo deja claro cuando prefiere dejar las cintas grabadas a sus hijas al médico, porque a Don se le olvidaría dárselas o les daría dos a la vez. es cuando le están haciendo pruebas a la protagonista en el hospital. Ann está preocupada por sus hijas que estarán esperándola en la puerta del colegio, y no piensa tanto en los resultado de las pruebas sino en la necesidad de que alguien avise a su madre para que vaya a recoger a las niñas. Nadie la escucha hasta que una enfermera empatiza con ella tras verse así misma de niña esperando con la nariz congelada a que la recojan (escena 1). La empatía una vez más es una herramienta más para comprender al otro y a uno mismo.

Más tarde, cuando el médico le dice a Ann que va a morir, se muestra de nuevo una acercamiento empático entre personajes. Las palabras de Ann no reflejan la tensión o la desesperación propias de una situación como esa, y de ellas se desprende por el contrario ironía y humor, así afirma: "Y yo que pensé que estaba embarazada", o "Ah, (el tumor) va muy rápido"); con todo, el médico empatiza y se compadece de ella, pero no está acostumbrado a empatizar y siente que no tiene palabras, entonces opta por gesto sencillo y cercano que es ofrecerle un caramelo (escena 1).

En La vida secreta de las palabras, se muestran también las contrariedades que aparecen en los actos comunicativos cuando faltan el respeto y amor en las relaciones humanas. Hanna es una persona que se refugia en el silencio, entre otras cosas porque ha perdido la fe en los seres humanos. Ella es sorda (por las secuelas de la tortura), y normalmente decide aislarse del mundo apagando el aparato de su oreja. En las primeras secuencias de la película Hanna trabaja tediosamente en una fábrica y se desconecta del mundo. Su silencio se ve solamente interrumpido por el altavoz de su jefe que le insta, sorprendentemente, a tomarse unas vacacio- 
nes (escena 1). Hanna vuelve, entonces, a su casa, un espacio con apenas muebles, cena de nuevo lo que previamente había comido en la fábrica (arroz blanco, pollo y manzana), no tiene televisión, ni contacto con nadie. Lleva una vida completamente alineada. Cuando por casualidad escucha que necesitan una enfermera para el cuidado de un enfermo en una plataforma petrolífera aislada, no duda en ofrecerse, para escapar y mantenerse ocupada. Hanna huye de sí misma y por tanto también del contacto con otros, por eso habla poco y también miente afirmando llamarse Cora y ser pelirroja. Además, no quiere oír, porque desconfía de las palabras. Es estremecedor cuando relata cómo uno de los soldados de la ONU la viola diciéndole al mismo tiempo al oído "Perdóname, lo siento". En contraste, el personaje de Josef en la película, temporalmente ciego por el accidente, utiliza el lenguaje en exceso, con ironías, bromas, humor, lo hace también como escudo para suplir su falta de visión y, sobre todo, para refugiarse del dolor que le causa recordar que su mejor amigo se ha suicidado en el incidente de la planta petrolífera al enterarse de la relación amorosa que mantenían Josef y su mujer. Es él el que le sugiere el nombre de Cora, retomando un cuento de una enfermera que cuida de un niño de 15 años del que finalmente acaba enamorándose. Estas y otras historias, son contadas por Josef en clave de humor, aunque detrás se esconde también mucho dolor. Como la historia del patín acuático, en la que su padre lo lanzó al agua sabiendo que ninguno de los dos sabía nadar (escena 4).

A veces la falta de comunicación verbal se intenta suplir con otros lenguajes más sensibles (más sensoriales) para reconectar con los otros. Coixet lo explica en varias escenas valiosas de estas películas. En Mi vida sin mí está, por ejemplo, la escena en la que Ann va a visitar a su padre a la cárcel. Le habla de sus hijas, de su vida. El padre intenta explicar por qué la madre lo odia y comenta que "Algunas personas... no pueden llevar la vida que los demás quieren que llevemos. Por mucho que lo intentas, no puedes (...) Es duro...saber... que quieres a alguien y no puedes hacerle feliz. Es como quererlos y...no poder quererlos como a ellos les gustaría ser queridos". En esta escena llega un momento en que Ann cesa de hablar y le dice a su padre que necesita tocarle la cara, que se acuerda de su tacto (escena 11).

En La vida secreta de las palabras destaca la secuencia en la que Hanna le cuenta a Josef lo que le ocurrió en la guerra de Bosnia. En esa escena tan emotiva, Josef es entonces incapaz de hablar, solo acaricia a Hanna para mostrarle su compasión; y Hanna es incapaz de ser sincera y cuenta lo que le ha pasado como si le hubiera ocurrido a otras mujeres, así por ejemplo la muerte de su hija, que es probablemente lo que le causa más pesar (es entonces cuando se comprende esa voz en off de una niña que desde el principio aparece invisible en la vida solitaria de Hanna). Hanna es incapaz de explicar su padecimiento y, al darse cuenta de la insuficiencia de su relato, prefiere que le toquen sus cicatrices para expresar con el tacto lo que no pueden expresar las palabras: las cicatrices comunican mejor la violencia que ha sufrido; son marcas, escritura de la violencia en el cuerpo que ha padecido el horror (escena 6).

El acto comunicativo precisa a veces de lenguajes sensoriales que reconecten a los individuos. El de la música es fundamental para el personaje de Lee en $\mathrm{Mi}$ vida sin mí. Su hermana le regala cintas de música y él las usa con Ann para mos- 
trar su sentimientos y expresarse. Este lenguaje comunica y Ann también se enamora de Lee, aunque siga queriendo a su marido (escena 7). El de la comida es el lenguaje principal de otro de los personajes de La vida secreta de las palabras, Simon (Javier Cámara), quien se expresa y vive a través de los platos internacionales que cocina, y quien intenta acercarse a los demás a través de ellos. De hecho, el despertar de Hanna comienza tras probar casi con violencia la parte de la cena sobrante de Josef. Ella siempre comía lo mismo (arroz, pollo y manzana), y la variedad de sabores de los platos de Simon le transmiten sus ganas de vivir (Cerrato, 2008: 148). El despertar es violento, rápido, y Coixet, cámara en mano, utiliza planos cortos que en el montaje se solapan con rapidez transmitiendo hábilmente la violencia de manera visual (escena 3).

Ambas protagonistas despiertan de su letargo para encontrase así mismas. Cuando Ann de Mi vida sin mítoma la decisión de no decir nada acerca de su enfermedad, y de este modo estar "sola" como ella misma afirma ${ }^{16}$, empieza a pensar que su vida ha sido un sueño del que comienza a despertar. Por eso comenta en voz en off: "Pensar. No estás acostumbrada a pensar. Cuando tienes tu primer hijo a los diecisiete años con el único hombre al que has besado, y después otro hijo a los diecinueve, con el mismo hombre...y vives en un remolque en el patio trasero de tu madre y tu padre lleva diez años en la cárcel, no tienes tiempo de pensar. A lo mejor has perdido tanto la práctica que ya no sabes cómo se hace" (escena 3). En ese momento recapacita y hace fríamente una lista de las diez cosas que le gustaría hacer antes de morirse: decir a sus hijas

16. "Sola. Estás sola. Nunca has estado tan sola en tu vida. Las mentiras son tu única compañía". que las quiere varias veces al día, encontrar una pareja para Don que le guste a las niñas, grabar mensajes de cumpleaños a sus hijas hasta que tengan dieciocho años, organizar un picnic en Whaleybay Beach, decir lo que piensa, hacer el amor con otros hombres para ver cómo es, ir a ver a su padre a la cárcel, ponerse uñas postizas y hacer algo con su pelo (escena 3). En su conjunto se intuye esa naturaleza humana contradictoria que gira entre el egoísmo y el altruismo, pero lo más Ilamativo para el espectador no es quiera acostarse con otro hombre o pintarse las uñas, es lo segundo: el que se interese especialmente por los que la sobrevivirán, el querer organizar el futuro de su familia para que sufran lo menos posible. En la película se muestran numerosas secuencias y planos en los que Ann va redescubriendo la importancia de las pequeñas cosas, los besos, los abrazos, el roce corporal; el centro de su existencia y su propio yo es la relación con sus seres queridos.

Para Hanna de La vida secreta de las palabras, su despertar al mundo empieza en un lugar alejado de todo, donde se reúne con un grupo reducido de personas que "solo quieren que les dejen en paz" (así lo expresa el encargado de la plataforma -escena 3-); son personas que sin embargo se encuentran consigo mismas gracias a la relación con los otros. Hanna es incapaz de racionalizar lo que le ha ocurrido y ello la ha bloqueado también emotivamente: es incapaz de sentir, de reír, llorar, disfrutar de los alimentos. Lo que propone Coixet es que para recuperar el sentido de la realidad y ser consciente de quienes somos, hay que hacerlo a través de otros lenguajes más sensibles (el gusto, el tacto, el oído, el olfato), y que esta es la manera de recuperar la propia identidad (escena 1 de Mi vida sin mi). 
Con todo, lo esencial para conformar al sujeto y redescubrirse en la filmografía de Coixet es el amor. Para Ann lo único que le hace sobrellevar la tensión esos dos meses de existencia antes de morir es el amor que siente por Don y sus hijas, por su madre, su amiga y también por Lee. La escena de la lavandería sorprende especialmente por su simbolismo. La lavandería es un lugar emblemático en la poética de Coixet al ser un sitio público donde se hace algo tan íntimo como lavar la ropa, es decir, donde lo privado se hace público. En esta escena Ann se encuentra con Lee y mientras él le trae un café, ella se queda dormida. A partir de entonces los planos se suceden lentamente pues paulatinamente se va a acercando Lee con su silla para mirar más de cerca y hasta que se hace de día a Ann (escena 4). Con su mirada, sabemos que se ha enamorado de ella. Ann despierta entonces, como si volvería a nacer. La escena en que se despide de Lee dando a entender que ella quiere a su marido, es esencial para comprender la importancia de Lee para Ann. Coixet utiliza aquí un movimiento de cámara que sigue a Lee y que luego vuelve a ella para quedarse fija, apareciendo de repente Lee para besarla. No se puede obviar la importancia de las relaciones con los seres queridos, porque son esas relaciones las que configuran nuestra subjetividad (escena 11).

El amor es también lo que realmente logra la recuperación de Hanna. En La vida secreta de las palabras, además, la empatía y la compasión resultan primordiales en el amor. Hanna empatiza y se compadece de Josef y también de su amante cuando escucha una y otra vez el mensaje que ésta le ha dejado en el móvil. Intenta mostrar su compasión con una caricia cuando Josef confiesa su pesar, aunque la rechaza alegando que "es horrible despertar compasión" (escena 5). Por su parte, Josef empatiza y se compadece de Hanna cuando ésta le cuenta su historia de guerra y lo hace también a través de una caricia (escena 6). La diferencia es que Hanna no le rechaza. Entonces Josef comprende la importancia de la compasión puesto que nadie más que Hanna le enseña cómo se puede vivir con el pasado y con los muertos, pues su historia es aún más violenta y conmovedora que la suya, al haber sido retenida con otras 15 mujeres en hotel, sistemáticamente violada por los suyos y por los supuestos salvadores soldados de la ONU, torturada con cortes en la piel a los que echaban sal, y obligada a sobrevivir tras el asesinato de su hija. La escena acaba con un abrazo y un beso muy conmovedores, que dan una oportunidad de vida a ambos.

Aquí volvemos a la teoría, el amor es esencial para definir al ser humano, y también lo es, aunque se intente ignorar en la sociedad actual, la muerte. En Mi vida sin mí, la voz en off de Ann afirma: "Ahora veo las cosas claras. Miro los escaparates y las cosas que no puedo comprar y ya no quiero. Todo está ahí para mantenernos lejos de la muerte, y no sirve". También en la escena en el supermercado aparece el tema de la muerte. El supermercado le gusta porque hace frio, el frio le hace sentir viva, y asimismo es un lugar donde nadie piensa en la muerte. La escena deviene onírica porque Ann valora ese pequeño acto de ir a comprar, y por eso todos aparecen bailando mientras hacen sus tareas. (escena 8). En el caso de La vida secreta de las palabras Hanna ha convivido directamente con la muerte y ha sentido el horror muy de cerca. La pregunta es la misma en ambas películas: cómo se puede sobrevivir a los muertos. 
En ningún caso se recurre a Dios. Ann se preocupa de los suyos cuando ella ya no esté; Hanna tiene que seguir viviendo a pesar de la vergüenza de haber sobrevivido al horror, y de sobrevivir a su hija a quien imagina crecer y acariciar el pelo. La respuesta es que solamente se sobrevive por amor.

El amor es el centro de las relaciones intersubjetivas; es el primer estadio de reconocimiento recíproco, en el que los seres humanos se ven unidos al verse como entes necesitados, dependientes de otros. Las relaciones afectivas siempre están en un equilibrio precario entre la autonomía y conexión (el ejemplo más claro están en la relación madre-hijo). Al ser el primer estadio de reconocimiento, el amor es igualmente esencial para el Derecho que, al guiar las conductas individuales, debe encontrar formas ampliadas de reconocimiento recíproco institucional y culturalmente (Honneth, 1997: 115).

La concepción liberal de la Justicia se ha centrado en el reconocimiento de iguales derechos individuales, pero lo ha hecho en un sentido meramente negativo, esto es, basado en la idea de no-interferencia por parte de otros. Sin embargo, es crucial apoyar el respeto hacía uno mismo en un sentido positivo, es decir, confirmando un concepto de hacer para que todos se sientan seres capaces, dignos e iguales derechos dentro (perteneciendo a) una sociedad o grupo particular. De ahí que: "Desde el enfoque del reconocimiento recíproco, la garantía de derechos no asegura la autonomía directamente (en el sentido negativo que evita las interferencias), sino que lo que permite la autonomía es el auto-respecto" (Anderson y Honneth, 2005: 133).

Además, para ser autónomo se requiere autoconfianza en los sentimientos, de- seos, impulsos y emociones propios. La autoconfianza es un proceso interpersonal de diálogo con uno mismo en el que parecen intervenir directamente el emoción y el apoyo de los demás. Por eso: "para proteger y fomentar las condiciones para la autonomía se deben proteger el tipo de relaciones donde se fragua la confianza en uno mismo. Por ejemplo, las relaciones familiares y las de trabajo" (Anderson y Honneth, 2005: 135, traducción propia).

Para ser autónomo también se precisa autoestima. La humillación social de ciertos tipos de vida y decisiones humanas mina la autonomía de los seres humanos. En este sentido, el contexto semántico y símbolo social es relevante, porque utilizando ciertas expresiones se pueden estar marginando opciones de vida de seres humanos, lo que limita también su capacidad de decidir. "Para proteger la autonomía se necesite luchar contra cualquier efecto degradante" (Anderson y Honneth, 2005: 137, traducción propia). La humillación "Es un tipo de conducta o condición que constituye una buena razón para que una persona considere que se le ha faltado al respeto" (Margalit, 1997: 21). En esta línea Avishai Margalit ha defendido que una sociedad decente es aquella cuyas instituciones no humillan a las personas, es decir, aquella que combate las condiciones que justifican que quienes forman parte de ella se consideren humillados o creen tener razones para sentirse humillados. Además, es aquella que acuerda respetar, a través de las instituciones, a las personas sujetas a su autoridad (1997: 15, 18, 22). De hecho, una sociedad que respete los derechos de las personas no es condición suficiente para considerarla una sociedad decente, puesto que puede humillar a sus miembros en tanto ciudadanos, aun cuando no viole unos derechos reconocidos. 
Para terminar, me gustaría mencionar otro tema sugestivo planteado en estos largometrajes: la memoria. En Mi vida sin mí y en La vida secreta de las palabras las grabaciones son fundamentales para la memoria. Ann graba mensajes en cintas a sus hijas en sus cumpleaños y a sus seres queridos: a su madre para que no se torture por no haber conseguido sus sueños, a Don para que no la eche de menos y se enamore de la otra Ann que vive en frente y le gusta a las niñas, y a Lee para que olvide a la mujer que lo dejó y pinte y compre muebles nuevos para su casa. En sus mensajes explica que les ha querido evitar el dolor de la enfermedad, y les insta a vivar su vida intensamente. Las cintas hacen de la vida un bien preciado, manteniendo presente en la memoria la figura de Ann cuya existencia es proyectada al futuro, especialmente en los mensajes que sus hijas recibirán en cada uno de sus cumpleaños.

Por su parte, Hanna no solo ha contado su historia a Josef, también se la ha narrado a Inge Genefke (interpretada por Julie Christie en la película), un personaje real que trabajó en la ONG International Rehabilitation Council for Torture Victims. Aquí Coixet, como en otras de sus películas, valora la labor de las organizaciones sin ánimo de lucro, que persiguen fines sociales ${ }^{17}$. Cuando Josef va a buscarla gracias a las cartas que le mandaba Inge a Hanna y que ésta olvidó junto a su mochila, pregunta por qué graban cintas de video con los testimonios de las experiencias vividas. Inge explica que "Antes del holocausto, Adolf Hitler reunió a todos sus colaboradores y, para convencer-

17. Incluso en esta película aparece un personaje comprometido con una causa, Martin, que detrás de su trabajo, en realidad, está más preocupado por el impacto medioambiental. los de que su plan funcionaría, les dijo: ¿Quien se acuerda del exterminio armenio?. Eso les dijo. Treinta años después, nadie recordaba que un millón de armenios habían sido exterminados de la manera más cruel posible. Han pasado diez años; ¿quién se acuerda de lo que pasó en los Balcanes? Los supervivientes. Los que, por alguna...argucia del destino, han vivido para contarlo; si es que pueden... Los que se avergüenzan...de haber sobrevivido. Como Hanna. Ésa es la ironía, si puede llamarse así: la vergüenza que sienten los que consiguen sobrevivir. $Y$ esa vergüenza, que es más grande que el dolor, que es más grande que cualquier cosa, puede durar para siempre" (escena 7).

La escritura, en este caso a través de las grabaciones en video de las experiencias vividas por las víctimas, es memoria, son historias personales que enriquecen el relato de la historia de una guerra. Se introduce aquí el tema de los metanarrativas y los micronarrativas. De este modo Coixet pasa de la ficción a la realidad, haciendo reflexionar al espectador sobre el concepto de historia en el sentido derridiano como conjunto de relatos fragmentados frente al único relato oficial impuesto. Como en la novela de El cuento de la criada de Margaret Atwood, la grabación de su protagonista es un testimonio de lo ocurrido en primera persona, una versión subjetiva, seguramente incompleta de lo que sucedió. Al final de la novela de Atwood, un grupo académico de profesores debaten sobre su relato, y lo identifican con lo personal, subjetivo, relativo frente a la narración oficial impuesta por la historia, y apoyada por el poder. No obstante, una narración, aún hegemónica, no puede ser suficiente para dar cuenta de la compleja realidad humana. Las narraciones femeninas son 
fundamentales no porque conformen una identidad sino porque permiten la reconstrucción crítica y reflexiva de los sujetos donde el amor, la esperanza y el perdón son valores fundamentales.

\section{A modo de conclusión}

- En este trabajo parto de una triple visión: en primer lugar, de la filosófico-jurídica, que presupone necesariamente un estudio crítico-reflexivo; en segundo lugar, de la feminista que, para afrontar el poder patriarcal, se ocupa de los aspectos jurídicos discursivos y también de los no discursivos y de lo que ha sido silenciado por el sistema, especialmente la afectividad como pilar de la existencia humana; valoro además principalmente ciertas propuestas comunitaritas que proponen la idea de un sujeto relacional; por último, parto de las Humanidades, ya que el carácter total de la Filosofía del Derecho hace que el jurista se interese por multitud de cuestiones y ramas del conocimiento, y entre ellas el cine puede ser una herramienta para cuestionar el monopolio de la inteligencia racional en el Derecho, y el injusto olvido de la inteligencia emocional.

- El cine de Coixet se funda en una visión emocional y empática de concebir el medio cinematográfico, y se vale de ella para ofrecer un concepto relacional de los individuos basando la subjetividad y autonomía en el amor hacía otros. Sus personajes son seres solitarios que han perdido la razón de su existencia, que están perdidos, alineados, y solamente consiguen despertar de su letargo gracias a la relación con otros y, especialmente, al amor.

- Los seres humanos tienen una naturaleza contradictoria, buscan la independencia pero a la vez son dependien- tes de otros. El amor hacía otros es el primer estadio que configura la propia subjetividad y permite la comunicación. Por eso la reivindicación femenina de recuperar el valor de las pequeñas cosas, de lo cotidiano, de la sensibilidad y el contacto con la naturaleza y con los demás es tan relevante para articular una nueva concepción del sujeto, más equilibrada, alejada de la mera autosuficiencia y del egoísmo. El amor, de hecho, está unido a la empatía y la compasión hacia otros. La teoría del Derecho y del sujeto jurídico deben hacerse eco de esta perspectiva renovada.

\section{Bibliografía}

Anderson, Joel and Honneth, Axel (2005) "Autonomy, Vulnerability, Recognition, and Justice", en Christman, John and Anderson, Joel (eds.), Autonomy and the Challenges to Liberalism: New Essays, New York, Camdbrige University Press, pp. 127-149.

Ansuátegui Roig, Francisco Javier, (1995) "Sobre algunos rasgos caracterizadores de la Filosofía del Derecho", Anuario de Filosofía del Derecho, Tomo XII, pp. 175194.

Botero, Andrés (2008) "Derecho y Literatura: un nuevo modelo para armar. Instrucciones de uso", en Calvo González, José (coord.) Implicaciones Derecho y Literatura: contribuciones a una teoría literaria del Derecho, Granada, Comares, pp. 29-40.

Butler, Judith (2007) El género en disputa. El feminismo y la subversión de la identidad, trad. M. A. Muñoz Molina, Barcelona, Paidós.

Calvo González, José (2014) “Cine y argumentación jurídica: estrategias y técnicas argumentativas y para-argumentos del 
alegato judicial en la litigación de los hechos", Teoría y Derecho: revista de pensamiento jurídico, núm. 16, pp. 280-307.

Castro, C. de (coord.) (1999) Problemas básicos de Filosofía del Derecho: desarroIlo sistemático, Madrid, Universitas.

Cerrato, Rafael (2008) Isabel Coixet, prol. Sarah Polley, Madrid, Ediciones JC.

Einsenstein, Sergei (1974) El sentido del cine, trad. I. Carballo, Buenos Aires, Siglo $\mathrm{XXI}$.

- (1970) Reflexiones de un cineasta, prol., ed., y notas de R. Gubern, BarceIona, Lumen.

Díaz García, Elías (1974) Sociología y Filosofía del Derecho, Madrid, Taurus.

Jaramillo, Cristina (2000) "La crítica feminista al Derecho", est. prel. a West, Robin, Género y Teoría del Derecho, trad. P. Lama Lama, Santafé de Bogotá, Siglo del Hombre Editores, Facultad de Derecho de la Universidad de los Andes, Ediciones Uniandes, Instituto Pensar, pp. 27-66.

Fraser, Nancy y Honneth, Axel (2006) ¿Redistribución o reconocimiento? Un debate político-filosófico, trad. P. Manzano, Madrid, Morata.

García López, Daniel (2016) Rara Avis. Una teoría queer impolítica, Barcelona, Melusina.

García Manrique, Ricardo y Ruiz Sanz, Mario (2009) El Derecho en el cine español contemporáneo, Valencia, Tirant lo Blanch.

Gómez García, Juan Antonio (ed.) (2008) El derecho a través de los géneros cinematográficos, Valencia, Tirant lo Blanch.

González Romero, Emilio (1997) Otros abogados y otros juicios en el cine español, Barcelona.

Honneth, Axel (1997) La lucha por el reconocimiento: por una gramática moral de los conflictos sociales, trad. M. Ballestero, Barcelona, Crítica.

- (2007) Reification: A New Look at an Old Idea, Oxford, Oxford University Press. Kennedy, Duncan (1979) "The Structure of Blackstone's Commentaries", Buffalo Law Review, n. 28, pp. 209-382. Disponible en: http://duncankennedy.net/ documents/Photo\%20articles/The\%20 Structure\%20of\%20Blackstones\%20 Commentaries.pdf (12 de junio de 2018).

Kracauer, Siegfried (1989) Teoría del cine. La redención de la realidad física, trad. J. Hornero, Barcelona, Paidós.

Lauretis, Teresa De (1992) Alicia ya no. Feminismo, semiótica, cine, Madrid, Cátedra.

MacKinnon, Katherine (1989) Hacia una teoría feminista del Estado, trad. E. Martín, Cátedra, Madrid, Universitàt de València, Instituto de la Mujer.

Marí, Enrique (1998) "Derecho y Literatura: algo de lo que sí se puede hablar pero en voz baja", Doxa. Cuadernos de Filosofía del Derecho, núm. 21, pp. 251-287.

Margalit, Avishai (1997) La sociedad decente, trad. C. Castell Audela, Barcelona, Paidós.

Mulvey, Laura (2009) Visual and other pleasure, United Kingdom, Palgrave Macmillan, Houndmills.

Ortega Jiménez, Alfonso y Cremades García, Purificación (2008) Cine y Derecho en 13 películas, Alicante, Club universitario.

Posner, Richard A. (2004) Ley y Literatura, trad. P. Salamanca y M. Muresán, Valladolid, Colegio de Abogados de Valladolid/ Cuatro y el gato.

Presno Linera, Miguel Ángel (2006) Una introducción cinematográfica al Derecho, Valencia, Tirant lo Blanch. 
Rivaya García, Benjamin (2006) "Sobre el carácter crítico de la Filosofía del Derecho", RDUNED. Revista de Derecho de la UNED, núm. 1, pp. 275-300.

- (2004) Derecho y Cine en 100 películas, Valencia, Tirant lo Blanch.

- (2008) El cine de los derechos humanos", en VVAA., Estudios homenaje al profesor Gregorio Peces- Barba, vol. 3, Madrid, Dykinson, pp. 1059-1082.

- (2010) "Derecho y cine", en Rivaya García, Benjamín y Zapatero, Luis (coords.) Los saberes y el cine, Valencia, Tirant lo Blanch, pp. 81-118.

- (2010) "Algunas preguntas sobre Derecho y cine", Anuario de Filosofía del Derecho, núm. 26, pp. 219-230.

- (2012) "Los derechos fundamentales en imágenes. Cine "de" y "contra" los derechos humanos", en Riviriego Picón, Fernando (coord.) Proyecciones de Derecho constitucional, Valencia, Tirant lo Blanch, pp. 145-188.

Sansone, Arianna (2001) Diritto e Literattura, Una introduzione generale, Milano, Giuffrè.

Selva, Marta y Solà, Anna (2002) "El cine de mujeres es el cine", en Selva, Marta y Solà, Anna, Diez años de la muestra Internacional de Filmes de Mujeres de Barcelona, Barcelona, Paidós.

Soto Nieta, Francisco y Fernández, Francisco Javier (2004) Imágenes y justicia. El Derecho a través del cine, Madrid, La leyactualidad.

Talavera, Pedro (2006) Derecho y Literatura, Granada, Comares.

West, Robin (2000) Género y Teoría del Derecho, trad. P. Lama Lama, Bogotá, Siglo del Hombre Editores, Facultad de Derecho de la Universidad de los Andes, Ediciones Uniandes, Instituto Pensar, [(1988) "Jurisprudence and Gender", University of Chicago Review, 55(1), 1-72].
- (1997) Caring Justice, New York/London, New York University Press.

Wittig, Monique, (2010) El pensamiento heterosexual, trad. J. Saéz y P. Vidarte, Barcelona, Egales. 